\title{
History Lived and Learned: Students and Vietnam Veterans in an Integrative Study Abroad Course
}

\section{Ray mond M. Scurfield}

University of Southern Mississippi

Leslie P. Root

Andrew wiest

University of Southern Mississippi

with F.N. Coiro, H.J. Sartin, C.L. Jones, and M. B. F a n u ga o

\section{Introduction}

In May 2000, the College of International and Continuing Education and the History Department at the University of Southern Mississippi (USM) sponsored an innovative study-abroad course on the history of the Vietnam War. As part of the course, three Vietnam combat veterans accompanied eight undergraduate and eight graduate history students to Vietnam. The course's staff included three members of the history faculty, a social-work faculty member, a psychologist, and a cameraman. This precedent-setting study abroad course integrated the teaching of Vietnam culture and military history with an exploration of the mental health aspects of combat and post-war recovery of Vietnam veterans. This article discusses lessons learned in designing and implementing the course, and implications regarding the integration of history education and therapeutic mental health objectives. 
Raymond M. Scurfield, Leslie P. Root and Andrew Wiest

\section{B a c kground}

As part of Andrew Wiest's course on the history of the Vietnam War at USM, he brought students to the Department of Veterans Affairs Medical Center in Gulfport, Mississippi with the goal of assisting the students in "putting a face" on the historical information they had learned. Dr. Leslie Root, at that time director of the VA's Posttraumatic Stress Disorder Clinic there, arranged for Wiest's students to meet two Vietnam veterans diagnosed with Posttraumatic Stress Disorder (PTSD), and for the veterans to discuss with the students the personal impact of the war. One of these veterans, as a result of his positive experience in the discussion, became a resource person for several subsequent Vietnam history courses at USM. He and several other Vietnam veterans appeared as guest speakers for the course, their personal accounts complementing the traditional lecture offerings on Vietnamese history and culture and the Vietnam War. Enrollment in this campus-based course increased as word spread about the powerful inclusion of Vietnam veterans as active participants.

Wiest's idea of returning to Vietnam arose from his observations of one veteran's, John Young, significant contribution to the course and the students' positive response to him as a regular speaker. Wiest noticed, too, that Young had benefited: sharing his experiences with the students seemed to be personally healing. Wiest approached Young with the idea of returning to Vietnam together with students, in the context of a Vietnam history course. In discussions between Wiest and Root, the idea grew into involving three veterans, with varying levels of PTSD, in a Vietnam history course that included travel to Vietnam. The veterans would contribute to the learning experiences of the students, and the travel-study experience would offer a positive experience to the veterans as part of their continuing post-war readjustment. Raymond Scurfield (a Vietnam veteran himself), was asked to join the course-planning group because he had accompanied a therapy group of eight veterans to Vietnam in 1989 and had led innovative "in action" therapy activities, such as helicopter-ride therapy and Outward Bound wilderness experiences (see Scurfield, Leong and Zeerocah, 1992; Hyer, Scurfield, Boyd, Smith and Burke, 1996).

Based on Scurfield's expertise in PTSD therapy, the course's developers recognized that inn addition to the impact on the history students, this project would offer the participating veterans the opportunity for 
Frontiers: The Interdisciplinary Journal of Study Abroad

growth, and for movement from trauma victim to trauma survivor. It would offer the veterans an opportunity to establish positive connections to society, as one course objective would be to communicate, through written accounts, media interviews and the production of an educational video, the value of their experience. These positive experiences are important for veterans. Interactions with university students would be particularly significant because university students are a cohort with whom many Vietnam veterans have had unresolved, mixed or negative issues, stemming from the anti-war movement that involved many university students during the war. The integration of university students and Vietnam veterans became a distinguishing feature of this course.

Because of the significant logistical and administrative challenges of implementing this course for the first time, it took almost two years to develop it fully. The focus of the course was twofold: the veteran-student interaction in a history-based course, integrated with direct exposure to the people and culture of current-day Vietnam. As an important part of the course plan, the veterans would share aspects of their war and post-war experiences with the students before, during, and after visits to the veterans' former battle sites in Vietnam. The course was designed to facilitate experiences that would be meaningful for the veterans. Student interaction with veterans was envisioned as a way to bring the war and its impact on veterans to life for the history students in a way not otherwise possible, an objective that had already been realized, to some degree, by having veterans as guest speakers in other courses. In the on-site portion of the course, these veteran-student interactions would be enriched by daily interaction with the Vietnamese people and culture, interspersed with visits to relevant former battlefields.

The course's didactic presentations on Vietnam military, cultural and religious history and travel to salient locations throughout south and central Vietnam were complemented by the veterans' oral histories. Other academic elements included presentations on war-related PTSD, psychological war-zone and post-war survival, mental health treatment of acute military psychiatric casualties and long-term, post-war readjustment. Therapeutic "group debriefings" in Vietnam, with all course participants to discuss their emotional reactions and experiences, contextualized the on-site experiences [See Appendix I]. 
Raymond M. Scurfield, Leslie P. Root and Andrew Wiest

\section{Selected Literature Review}

According to Snyder (2000), the dominant mode of instruction in the United States has been described as "frontal teaching" or "chalk talk." In Snyder's study, the majority of high school students tested were described as global or tactile/kinesthetic learners who learned primarily by "seeing the whole picture of what they were trying to learn ... they learn best by actually doing things, not by just listening and watching. They need to be actively involved in constructing their own knowledge about the subject they are learning" (p. 16). Learning through participation is the rationale for many study abroad programs (Hudson, 2001). These programs allow students "to absorb information about societies and cultures in a form which no textbook can convey, as a result of direct contact with local people in their environment" (Panton and Dilsaver, 1989: 45; see also Davis, 1998; Hudson, 2001; Reghanzani, 1992; Tye, 1990).

In integrating students with Vietnam veterans, students witnessed veterans' oral histories and emotional reactions to long-held memories upon returning to former battlefields. The students learned about Vietnam War history in ways not possible from only reading books. The students acted as participant-observers, interacting with the veterans and offering their own responses and support. Furthermore, the interchange between students and veterans occurred in the context of contemporary Vietnam. Students observed and participated in "living history in the making," as students and veterans attempted to reconcile their disparate experiences of the peacetime Vietnam of today with their preconceived notions about the war-torn Vietnam of the past.

In addition to the anticipated educational benefits for students, there was a corollary set of anticipated therapeutic mental health benefits for the veterans. A substantial literature eloquently documents the narrative histories of military and civilian trauma survivors (Caputo, 1977; Edwards, 1992; Kovic, 1976; Santoli, 1981; Terry, 1984; Van DeVanter, 1983; and Walker, 1985). The relationship between survivors telling their oral histories and psychological recovery from trauma exposure also has been described (Meichenbaum, 2000; also Howard, 1991; Scurfield, 1994; Scurfield, in press). Meichenbaum describes how patients in psychotherapy come to "re-author" their accounts, constructing new narratives to tell their stories differently than they have been remembering them. 
Frontiers: The Interdisciplinary Journal of Study Abroad

Patients enter treatment with an account that reflects a sense of victimization, demoralization, helplessness, and hopelessness. They feel "victimized" by circumstances, by their feelings and thoughts, and by the absence of support from others ... How can therapists help patients change their accounts from being "victims" to becoming "survivors, or people who can "thrive"? ... In short, the construction of a new narrative emerges out of the actions that patients take to refashion their lives. Patients need to perform "personal experiments" in their everyday experience and take the data from these efforts as evidence to unfreeze their beliefs about themselves and the world. They need to begin to tell themselves new stories that move them from viewing themselves as "victims" to becoming "survivors" (pp. 58-59).

Based on this evidence, it seemed possible that the veteran-student interactions in Vietnam could be at least as powerful and therapeutic as the veterans' sharing of oral histories in counseling sessions with their therapists.

The scientific literature on the treatment of PTSD supports the necessity of "direct therapeutic exposure" to an aspect of the original trauma (Nicholson and Fairbank, 1988). Such therapeutic exposure involves the trauma survivor talking about his or her traumatic experience either in individual therapy or by participating in a discussion with fellow survivors (Scurfield, 1993; 1994; in press; Wiest, Root and Scurfield, 2001). Research posits that repeated exposure to aspects of the trauma in a therapeutic setting promotes habituation, reduces fear or anxiety associated with the trauma memory and fosters the realization that it is psychologically safe to remember the trauma. Also, the therapeutic reliving provides the opportunity to focus on memories that have been problematic, such as an exaggeration of the reality of having been able to prevent the trauma from occurring. This allows greater resolution of issues and impacted grief over loss (Rothbaum and Foa, 1999) and of realities that have been ignored, denied or minimized, for example, positive or heroic actions in the midst of chaotic events. Reported benefits of Vietnam veterans returning to Vietnam have included some resolution of war-related events and accompanying guilt, the experience of present-day positive memories of Vietnam, and an increased appreciation of their lives in their own country (Scurfield, 1989; Gerlock, 1991; Parson, 1990). 
The absence of literature describing a trip to Vietnam (or to any other former war zone), which combines veterans and university students and the dual educational and therapeutic objectives, required an exploratory mindset to implement and evaluate the USM course elements and potential positive and negative outcomes. It was assumed that implementing this unprecedented study abroad course offered a unique opportunity to evaluate the efficacy of such a project.

\section{History with Mental health Learning Objectives: Students with Veterans}

The course's goal was to enhance student learning through the veterans' oral histories while creating supportive and educational interactions that would provide therapeutic benefits to the veterans. The students enrolled in this course for academic credit, and veterans participated as resource personnel. This academic forum offered the advantages of full support and official sanction by the university of the curriculum's content.

Four of the 16 students had fathers or uncles who were Vietnam veterans and a fifth student had a relative who was a veteran of another war, and they were taking this course, in part, to better understand their family members' experiences. Other students were interested in the Vietnam War from a military history perspective, further stimulated by interacting with Vietnam veterans in on-campus classes. Thus, the opportunity existed for some students to deal with the impact of war on their family members and on themselves. Such personal connections raised the expectations of strong emotional reactions in Vietnam by students. As a result, mental health resource personnel were available for both the students and Vietnam veterans.

Negative factors associated with this student-veteran mixture were possible and could be exacerbated by the age difference between the veterans (average age mid-50s) and the students (average age mid-to-late20s). For example, there was a concern that these students might engage in partying, and worry that such behavior might diminish the serious nature of the trip for the veterans. Conversely, there was the worry that the veterans' experience would be so intense as to limit the students from engaging genuinely in the local culture, and truly benefiting from their educational experience abroad.

Students had expressed concerns that they might not behave appro- 
Frontiers: The Interdisciplinary Journal of Study Abroad

priately with the veterans while in Vietnam, especially during times of serious emotional reaction. Would the presence of 16 students, in contrast to three veterans, weigh the overall experience much more heavily toward history education over post-war recovery objectives? Or would the higher proportion of students ensure the attainment of academic learning objectives and promote a welcome balance to what otherwise might be a serious psychological experience for the veterans?

Ultimately it was recognized that, no matter how carefully planned and implemented, the veterans' experiences might be emotionally difficult and could provoke in them overwhelming war-related memories and reactions. Such reactions could be counter-therapeutic to the veterans and counter-educational, if not disturbing, to the students. It was viewed as essential to include trained mental health personnel to ensure the therapeutic aspect of exposure for all course participants.

\section{Course Participant Profile}

Of the history students, eight were female, and eight were male. The mean age was 28 years, ranging from 21 to 44 years. The modal age was 22. The Vietnam combat veterans who accompanied the class have permitted the following selections of their military information:

John Young: 4th Battalion, 47th Infantry, 9th Infantry Division, rifle squad leader, 1967-1969. Awarded Purple Heart, Bronze Star medal with V (valor) device and two Vietnam Service medals

Charles P. Brown: 4th Battalion, 173rd Airborne Brigade, platoon sergeant, 1967-1968. Awarded two Purple Hearts and two Bronze Stars with V (valor) device

Roy Ainsworth: 1st Battalion, 9th Marines, 1967. Awarded Purple Heart

Two of the veterans had longstanding psychiatric diagnoses of severe warrelated PTSD and had received mental health treatment for several years. The third veteran reported no history of psychological problems or mental health treatment related to service in Vietnam. None of the veterans had been to Vietnam since the war, and all three had positive experiences as guest lecturers for the USM Vietnam War history class. Additional selection criteria for veteran-participants, who were screened by the 
course's mental health personnel, included an interest in and willingness to interact with college students on the trip and to participate in all triprelated meetings and activities. Also, the veterans did not present any current or recent significant history of mental health or substance use problems that would put them unduly at risk for a relapse of PTSD.

\section{Course Finances}

This course was expensive in comparison to other study abroad opportunities offered by the university. One reason for the relatively high cost of the program was its elaborate infrastructure. For most study abroad courses at USM, there is one faculty member per class, and up to $25 \mathrm{stu}-$ dents. The Vietnam course staff included three traditional faculty members, the three veterans as non-traditional resource persons, two mental health personnel and a cameraman

International study abroad programs at USM are self-supporting, receiving no state or federal funding. As a result, the entire cost of the Vietnam studies program, including the six faculty members, was covered by student fees- $\$ 3,399$ each for the undergraduate students and $\$ 3,699$ each for the graduate students. The students understood the fee structure of the course and agreed that the extensive itinerary and the presence of veterans and mental health faculty members made the extra expense worthwhile.

\section{Course Structure}

Students received four semester-credit hours for this course. Requirements included prior completion of a university-level history course on the Vietnam War, participation in two pre-departure meetings, completion of questionnaires and evaluations, participation in all courserelated activities, willingness to be videotaped during course-related activities, and maintaining a course diary or journal. In Vietnam, the course consisted of lectures by historians, mental health personnel and veterans; field trips to historical and cultural sites; excursions to the specific battle sites and locations where each veteran had served during the war and eight 90-minute debriefings.

The curricular elements related directly to each veteran's former battlefield. Wiest gave a military history lecture specific to each site. The 
Frontiers: The Interdisciplinary Journal of Study Abroad

lecture was supplemented by the veteran orienting course participants. The veteran described his military unit, his position and responsibilities in the unit, and accounted the events and actions that unfolded there. The lecture and the veterans' presentation included questions from and interactions with the students. Finally, there was a mental health lecture, such as Root speaking on the dynamics of psychology and war, or by Scurfield considering the impact of war on combatants.

Admittedly, psychological debriefing sessions are not typical components of history courses. These sessions were designed to support the dual educational and therapeutic purposes of the trip. It was hoped the sessions would offer a supportive forum in which the students and the veterans could share and process their reactions during the activities in Vietnam - and, especially, to process the impact of the veterans' returns to their respective battlefields. The debriefings also served a pragmatic function as a time to share logistical information and schedule changes.

The debriefings were held after returning from each veteran's battle site. All participants sat in a large circle, and one of the mental health personnel would share significant experiences. Participants were invited to consider saying something, but they were instructed that speaking was not required. Typically, about three-fourths of the participants would share their reactions.

As an illustration, course participants were involved in an all-day excursion to Long An Province, where one of the veterans, John, planned to visit the Can Giouc battlefield, which had been the site of an extraordinarily violent battle that had continued to have a profound emotional impact on him. John was able to find the exact spot where the battle had occurred, and the villagers there were gracious to him and to the course participants. These facts combined with the coup de gras-meeting several former Viet Cong soldiers who still lived in the nearby village and actually had participated in the same battle-made this a poignant experience for all.

After returning from the battlefield, there was a debriefing of the day's events. The cameraman showed 30 minutes of video taken at the battle site. It was powerful footage, including John's interactions with two former Viet Cong and the other two veterans' interactions with other former Viet Cong at the nearby village. John then shared his reaction to the video, and a mental health debriefing was made available to course participants to process reactions and experiences. John described the losses 
and anguish suffered, as well as his amazement and gratitude at the former enemy's graciousness. He became emotional, as did many of the other course participants, as he described the horrors of battle and his feelings of helplessness and rage at the time, and how this intertwined with his experiences earlier that day.

Two of the questions asked by students of John during the debriefing illustrated the course's dual focus on mental health and military history:

Student: Did you get any closure out of your meeting today, meeting with the two former Viet Cong you had fought against?

Student: I hope it is not a diversion, but can you tell us about the battle itself?

During the debriefing, several other course participants shared their reactions to the day's events. For example, there were varying reactions to a meeting that the group had attended near the battlefield with two village Communist officials, who gave their rendition of "the glorious victory" that had occurred during that battle. Some of the course participants had negative emotional reactions to this politicized speech; others found it interesting. One common reaction during the debriefing was the feeling that the participants had been on an amazing journey transporting them back 30 years to the war while, at the same time, immersing them in the present-day reality of Vietnam.

\section{Program Evaluation}

This self-report program evaluation instrument was adapted from one developed after an 1989 veteran-only return trip to Vietnam (Scurfield and Burke, 1989). Course participants were asked to evaluate such factors as the sites visited, the didactic presentations by faculty, the mixture of history students and Vietnam veterans, the impact of the experience during and following the course, the perceived impact on the stress recovery of the Vietnam veterans and recommended course changes.

The items on the questionnaire were either open-ended, closed-ended or a combination of both (closed-ended with the option to write in a response). A Likert-like scale was used for the closed-ended items; respondents were 
Frontiers: The Interdisciplinary Journal of Study Abroad

asked to indicate their degree of agreement or disagreement with a series of statements concerning their perceptions or self-evaluation.

The response rates for completing the questionnaire were:
Students
$14(82 \%)$
Veterans
$3(100 \%)$
Faculty
$4(80.0 \%)$
Total Respondents
21 (84\% of the 25 total course participants)

The trip was described by respondents as highly positive in regard to their understanding about the Vietnamese people and culture $(100 \%$ of the respondents) and the Vietnam veterans and their experiences (95 $\%)$. All respondents praised their experiences during this course and the impact on themselves. Most striking, one-third of the respondents (33\%) commented that this course had been a peak life experience. For example:

Student: The whole experience made me rethink my purpose in life.

Student: The trip made me want to help people--both vets and the people of Vietnam. I came back with a new perspective and wanted to make a difference.

Although several aspects of the course were identified as stressful, 100 percent of the course participants who completed the evaluation indicated that they would highly recommend this course to other students, even if no modifications were made. Even those few areas that were not rated as well were highly rated by a substantial majority of the participants. Conversely, the aspects of the trip identified as negative or stressful were quite varied and, in almost all cases, were identified by less than 20 percent of the respondents. The most important findings concern several distinctive aspects of the course design.

\section{Mixture of Students and Veterans}

The student-veteran mixture was rated as highly positive by 100 percent of student, veteran and faculty respondents. Four positive aspects of this mixture were almost equally cited: (1) the students being in a role that was helpful to the veterans, (2) the opportunity to be witnesses to the 
veterans' sharing of their oral histories and the resultant connection to "real history," 3) learning new perspectives about history, and (4) the quality of the interactions between students and veterans.

The students reported that the student-veteran mixture was the most powerful enrichment of their learning about history, along with their experiences traveling in and being exposed to the country and people of Vietnam.

Student: That combination [of students and veterans] is what the trip was all about for me. Hearing their stories about their experiences was an honor. I can't say that I'm "impressed," just in awe of their strength and bravery and I wanted to go to show my support and to learn from them and that's exactly what I didI learned.

Student: [Having a mixture of veterans and students] made the war more real and the trips to the former battlefields were definite high points of the trip that changed my life.

Student: The trip would have lacked the intensity without them [the veterans] and would have paled in comparison. It is such an amazing opportunity to have veterans share their experiences.

Student: The magnitude of contact with Southeast Asia in the presence of U.S. veterans is incomparable.

The Vietnam veterans unanimously praised the value of going on this trip with the students. The opportunity to share their military oral histories in Vietnam with the students, along with returning for the first time since their war duty to salient sites of traumatic war events, were rated as highly positive experiences by the veterans.

Veteran: I've been trying all my life to say goodbye and yesterday [when visiting my former battlefield site] I finally had the chance, and without you [the students], I couldn't have done it.

Veteran: You could have spent the summer in Europe [on a study-abroad course], you could have spent the summer at home, but you sacrificed and came here and made this possible. If it weren't for you, I would have missed the most important day of my life. Thank you, thank you, thank you. 
Frontiers: The Interdisciplinary Journal of Study Abroad

Veteran: Their overall companionship, their appreciation, how respectful they were and understanding of going back with a vet for the first time. They were a delight-many had been through the Vietnam class, and I had prior exposure to them. They were able to relate the actual course material to the Vietnam trip experiences. I admire them and have a high regard for their making the trip at all.

Student comments reflect the beneficial reciprocity gained from having students and veterans together on this course:

Student: The veterans have much to teach, and we have so much to learn.

Student: [The combination of students and veterans] makes the trip more light-hearted—not so serious/somber all the time. Allows vets to open up more to inquisitive students.

It is noteworthy that 57 percent of the respondents reported absolutely no negative aspects of the student-veteran mixture. The only negative aspects mentioned by a few students were their perceptions that they had possibly "gotten on the veterans' nerves" at times, which the veterans denied, and the sometimes-conflicting motivation or purpose for the trip between veterans and students.

\section{Mixture of History and Mental Health: Educational and Therapeutic Objectives}

The combination of formal lecture and discussion of military history and mental health aspects of war, including PTSD and the treatment of psychiatric war casualties, was rated positively by 76 percent of the course respondents. Specific positive aspects of this combination included: the opportunity to understand the veterans' experiences $(33.3 \%)$, the different perspectives on the same experience provided by each discipline (29 $\%)$ and the presence of mental health personnel for students (15\%) and veterans $(20 \%)$.

Student: They had different things to offer. Dr. Wiest: historical perspective; 
Raymond M. Scurfield, Leslie P. Root and Andrew Wiest

Dr. Root: psychological perspective; Dr. Scurfield: sociological perspective.

However, there was ambivalence about this combination for several of the students:

Student: I liked understanding more about what the vets were going through.

Student: They [the mental health faculty] "therapized" a lot on the trip.

The didactic presentations on history and mental health content were highly rated as worthwhile by 100 percent and 95 percent of respondents, respectively. The two lowest-rated presentations were still rated highly by a substantial majority of respondents: the South Vietnamese view of the war $(75 \%)$, presented, incidentally, not by a Vietnamese historian but by a visiting professor from England; and the psychological debriefings $(71 \%)$.

Being required to participate in eight psychological debriefings received a mixed rating, which deserves a few observations. The psychological debriefings were identified as the second-most stressful experience in Vietnam. Despite being perceived as a stressful experience, a substantial majority of the course respondents $(71 \%)$ rated the debriefings as an important component of the course.

Student: These meetings [debriefings] were very important and I am glad we had them.

Student: Historians gave us history and the mental health people helped us cope with what we were experiencing.

On the other hand, six participants (28\%) were either neutral or critical of the debriefing experiences. Criticisms centered on three aspects. First, the debriefings were viewed as too long, too frequent and should have been made optional. Next, there was some discomfort with, or lack of interest in, being exposed to emotional sharing about experiences incountry. Finally, some participants perceived pressure to share feelings during debriefings when they only wanted to share cognitive observations or talk about historical events. Interestingly, the mental health personnel perceived that, by and large, the debriefings were conducted in a much 
Frontiers: The Interdisciplinary Journal of Study Abroad

less directive and more informal manner than a normal psychological debriefing. Participants were given considerable latitude not to participate in the sessions or to share only on a cognitive level.

A negative aspect of the history and mental health combination identified by 33 percent of the respondents was a perceived conflict of focus between these two disciplines. As described in the program evaluation, there seemed to be different emphases among the faculty members during the course:

Student: It appeared that there was a disagreement whether it [the course] should focus more on history or mental health.

\section{Most Meaningful Aspects of the Course}

Four of the most meaningful aspects of the trip identified by respondents were visiting the veterans' battlefields (38\%), veteran-student interactions (24\%), seeing veterans' experience Vietnam and the Vietnamese people (20\%), and observing the veterans' reactions to being in Vietnam $(20 \%)$.

Student: I gained a better understanding of PTSD and how it affects veterans.

Student: It made me see how hard and horrible Vietnam was to vets. It was an irrelevant concept to me before, but actually seeing where they had to go and what they had to do made it have meaning.

The second and sixth most salient experiences related to being in Vietnam were interacting with the Vietnamese people $(33.3 \%)$ and experiencing a third-world country $(20 \%)$. Visiting the battlefields with veterans was the most salient experience of the course for more of the participants than any other factor.

Student: My most positive experience of the trip was being there when [John] returned from his battlefield and pinned the [American] medals on his former enemies. It was a moment I will never forget. I was so proud of him and proud of myself for doing all that I had to do to be there to see it. 
Raymond M. Scurfield, Leslie P. Root and Andrew Wiest

Several of the students had been to other battlefields, for example, in France, but without veterans who had fought there. The "living history" aspect of this course was qualitatively different and distinctively praised.

Student: Can't get any better than learning history from someone who made history.

Student: Veterans' presence prevents students from becoming excessively distracted and links the trip to war history in an irreplaceable fashion.

\section{Lessons Learned}

Important lessons were learned regarding key elements of the course and the design and implementation of the program evaluation. The evaluation findings offer compelling support for the value of exposing students to living history through the veterans' narratives and visits to former battlefields, and the inclusion of mental health curriculum to complement more traditional history content. The utilization of mental health debriefings throughout the course was highly rated by almost three-fourths of the participants, although one-fourth found them to be problematic.

The evaluative data underscored the importance of better communicating, as part of the pre-departure preparation, the rationale and psychological importance of the debriefing sessions. Such efforts would need to be reinforced by systematically querying course participants while in Vietnam about their reactions to the debriefing sessions to insure optimal benefits for participants. An alternative would be to require participation in some debriefing sessions (e.g., the ones occurring immediately after battlefield visits) and to make participation optional at other debriefing sessions.

The data also revealed insufficient team building, understanding and appreciation concerning the different educational approaches of the history faculty and mental health personnel. It would be critical, in future courses, for faculty and staff to clarify the educational strategies utilized by each discipline. They should define the merits of the traditionally didactic instructional methods, which focus on military history strategies and tactics, and the psychodynamic orientation of the mental health instruction, which focuses on facilitating personal awareness and 
Frontiers: The Interdisciplinary Journal of Study Abroad

the verbal expression of underlying emotions and cognitions. In particular, it is important to educate history faculty and students about the objectives of critical-incident stress debriefings. The debriefings on-site in Vietnam were adapted from a protocol, with which few, if any, history faculty members or students would have been familiar (see, for example, Bell, 1995, and Mitchell and Everly, 1998).

The cross-disciplinary faculty members had assumed the different disciplines were congruent in valuing the narrative testimony of combat veterans, and, to a very important degree, they were. However, in retrospect, there were substantially different emphases on the content of such testimonies. While military-history faculty valued the veterans' emotional experiences, they valued at least as much, if not more, the veterans' perspectives on the tactical, operational elements of combat experiences. On the other hand, the mental health personnel were more interested in eliciting the veterans' psychological, cognitive and behavioral dynamics, the impact of combat trauma on physical and psychological survival in the war-zone and in post-war functioning, and the therapeutic benefits of expressing such in a supportive group milieu.

Lessons also were learned about the program evaluation instrument and the one-time collection of evaluation data four months after the return from Vietnam. There were no known validated instruments available to provide the kind of course-specific evaluative data to assess adequately this course and its impact on the participants. The development of a specifically designed instrument was considered essential, resulting in a newly constructed evaluation instrument that included closed- and open-ended items.

An overall 84 percent response rate for completed evaluation forms is commendable. However, the response rate could have been increased to nearly 100 percent by administering the survey within two weeks of returning from Vietnam and requiring the submission of a completed evaluation form in order to receive a grade.

The authors are satisfied with the item construction, which included closed- and open-ended items and queried course participants about every major activity and element. This strategy provided a wealth of descriptive data. The narrative data permitted a more complete understanding of why participants did or did not value elements of the course. For example, two comments illustrate how the qualitative data enabled a 
Raymond M. Scurfield, Leslie P. Root and Andrew Wiest

better understanding of the low ratings given by six of the 21 respondents to the debriefing sessions:

History faculty: Debriefings should be optional. Most of the group has no direct connection to Vietnam. The "sharing of feelings" sessions were a bit much.

Student: Discussions outside of these "touchy-feely" sessions, as others referred to them, made it clear to me that a number of students thought they were a waste of time, ridiculous and an exhibition of weak character. I didn't want to break down ... felt others were ridiculing me for it.

Such written comments helped the authors understand that this sub-group was neither comfortable with nor interested in exposure to emotional sharing. The above student observation also illustrates the persistent attitudes of some people, including a number of war veterans, toward emotional expression in the presence of others and toward mental health treatment.

The data also pinpointed perceived competing tensions between history and mental health curriculum content, evidence that cross-disciplinary collaboration, which had been assumed, needed to be better addressed in future courses. Such findings also raise the question of whether a mix of students from different fields of study would have resulted in different ratings of the course's mental health elements. It is important to note that even three years after the course ended, the authors are not aware of any important aspects of the course about which data had not been collected.

The data collected is limited because it was a one-time snapshot of the course participants' perceptions, taken four months after their return. Although no systematic effort was planned to obtain data at a second point in time, there were follow-up interviews, utilizing a series of interview prompts with the veterans, one year after the course ended. All three veterans indicated that this course continued to be a peak life experience and that it had been helpful (although not a panacea) in their post-war recoveries. Not one negative outcome of the trip was uncovered.

While not systematically obtained, informal communications with several of the students affirmed their continuing praise for the course. For 
Frontiers: The Interdisciplinary Journal of Study Abroad

future trips, the authors will consider a formalized follow-up, one year after completion of the course, to permit an A-B comparison with an initial survey, taken within two weeks of returning. It would be desirable to include samples of the students and veterans.

A final lesson concerns finances. The program failed to reach the break-even point due to the high costs of the extended infrastructure. One way to reduce costs, but maintain adequate staffing, would be to cut the number of faculty to one history faculty and one mental health staff member. A second possibility would be to seek private funding to subsidize, in part or in whole, the costs for veterans and/or to ask participating veterans to pay some portion of their expenses. A third possibility would be to increase the number of course participants, depending on careful assessment of logistical constraints. Increasing the number of student enrollees could be facilitated by having the course approved by other majors, say as a social work and/or psychology course, which would have the advantage of further enriching course objectives.

\section{Conclusion}

Unequivocally, participants considered the course to be a highly positive and memorable learning experience:

Student: The trip was one of the most extraordinary experiences of my life. I highly recommend it. The only negative aspect was that it was too short!

Veteran: Students made it a lot easier. They're laughing and joking takes your mind [off] things. And they cared, a lot, and showed real interest in learning about the war through their questioning and listening.

Students commented on the opportunity to accompany, observe and interact with the veterans in Vietnam:

Student: Accompanying the veterans to their battlefields [was the most positive experience in the course]. It was so positive in two ways. It helped me to understand and forgive my father [a Vietnam veteran] for being so uptight and "different" than 
Raymond M. Scurfield, Leslie P. Root and Andrew Wiest

other fathers were when I was a teen. And, I was so proud of and for the veterans that they had the courage to return to Vietnam and face their demons.

Student: Most important for me was going on the sampan with John and the former Viet Cong back to John's battlefield and walking in the rice paddy and observing the moments of John and the Viet Cong in the rice paddy. And I was looking out across the delta and realizing ... that this is just anyplace, and lots of young people were killed there, both Vietnamese and American.

Based on the program evaluation findings, it was concluded that any future study abroad courses to Vietnam include two core elements: a mixture of students and veterans and visits to the veterans' former battlefields. The authors also believe that if veteran participants in future courses have any history of treatment for war-related PTSD and other readjustment difficulties, or there is any question as to their psychological and social stability, then one or more mental health professionals must be available as resource personnel during the course.

The program evaluation results corroborate the distinctive experience and didactic learning for all course participants. For the students, there was an extraordinary learning experience about the living history of U.S. and Vietnamese veterans, the country and its people. For the veterans, there was a positive impact on their post-war stress recovery, attributable, in part, to the rich interchange between the veterans, the students and accompanying mental health support. For the history and mental health faculty, there was unique exposure to a cross-disciplinary endeavor and the different world views of each.

In the closing words on the evaluation instrument of four course participants:

Student: The stream of emotions I went through was overwhelming: happy, sad, honored, scared, blessed...

Veteran: Thanks very much for a positive picture/memory of a dark chapter in my life. I had had all the images from 1967-68 that I could ever hold-all of it was grim-the pain, the horror, none of that is gone. But now, I remember seeing, everywhere we went, everywhere we went, the people smiled at us. Now I 
Frontiers: The Interdisciplinary Journal of Study Abroad

have good memories - and that is worth a lot.

Student: Visiting the battlefields; learning more about the war was so meaningful. It meant so much more to actually see the vets at the battlefields and hear their stories instead of sitting in a classroom listening to a lecture.

Veteran: The souls of my comrades who never turned 20 can rest easier, since you [the students] took the time and have visited the place where their hearts last beat ... Thank you.

\section{References}

Astin, M.C. and Rothbaum, B.O. (2000). "Exposure Therapy for the Treatment of Post-traumatic Stress Disorder." National Center for PTSD Clinical Quarterly 9 (4), 50-54.

Bell, J.L. (1995). "Traumatic Event Debriefing: Service Delivery Designs and the Role of Social Work." Social Work, 40 (1), 36-43.

Caputo, P. (1977). A Rumor of War. New York: Holt, Rinehart and Winston.

Davis, T.M. (1998, October). Open Doors 1996/97: Report on International Education Exchange. New York: Institute of International Education.

Edwards, G.D. (1992). Vietnam, the War Within: Australian, American, New Zealand. Salisbury, South Australia: Glen E. Edwards.

Gerlock, A. (1991). Vietnam. "Returning to the Scene of the Trauma." Journal of Psychosocial Nursing, 29 (2), 4-8.

Howard, G.S. (1991). "Cultural Tales: A Narrative Approach to Thinking Cross-cultural Psychology, and Psychotherapy." American Psychologist 46, 187-197.

Hudson, D.R. (2001). Grade Point Average as a Predictor of Academic Achievement for a Credit Abroad, Language Acquisition Course. Unpublished dissertation, University of Southern Mississippi, Hattiesburg, MS.

Hyer, L., Scurfield, R.M., Boyd, S. Smith, D. and Burke, J. (1996). "Effects of Outward Bound Experience as an Adjunct to In-patient PTSD Treatment of War Veterans." The Journal of Clinical Psychology 52 (3), 263-278.

Kovic, R. (1976). Born on the Fourth of July. New York: McGraw-Hill.

Meichenbaum, D. (2000). “Treating Patients with PTSD: A Constructive 
Raymond M. Scurfield, Leslie P. Root and Andrew Wiest

Narrative Approach." Center for PTSD Clinical Quarterly 9 (4), 55, 58-59.

Mitchell, J.J. and Everly, G.S. (1998). "Critical Incident Stress Management: A New Era in Crisis Intervention." Traumatic Stress Points Fall 6-7, 10-11.

Nicholson, R. and Fairbank, J. (1987). "Theoretical and Empirical Issues in the Treatment of Post-traumatic Stress Disorder in Vietnam Veterans." Journal of Clinical Psychology 43 (1), 44-66.

Panton, K. and Dilsavaer, L. (1989). "Americans in Britain: Geographic Education and Foreign Field Trips." Journal of Geography in Higher Education 12(1), 45-53.

Parson, E. R. (1990). "Psychotour: Returning to Vietnam for Reconstructive Renewal. Post-traumatic Demoralization Syndrome (PTDS)." Journal of Contemporary Psychotherapy 20, 29-31.

Reghenzani, D.M. (1992). "Perceived Levels of Satisfaction with an International Educational Experience at a Selected American University." University of Southern Mississippi, Hattiesburg, MS.

Rothbaum, B. and Foa, E. (1999). "Exposure Therapy for PTSD. The National Center for Post-traumatic Stress Disorder." PTSD Research Quarterly 10 (2) Spring, 1-6.

Rothbaum, B., Hodges, L. Alarcon, R., Ready, D., Shahar, F., Graap, K., Pair, J., Hebert, P. Gotz, D. Wills, B. and Baltzell, D. (1999). "Virtual Reality exposure Therapy for PTSD Vietnam Veterans: A Case Study." Journal of Traumatic Stress 12 (2), 263-271.

Santoli, A. (1981). Everything We Had: An Oral History of the Vietnam War as Told by 33 American Soldiers who Fought It. New York: Random House.

Scurfield, R. M. (1989). Vietnam Revisited: Journey of Healing. Western Express, Vol, 1(2), June, San Francisco: Department of Veterans Affairs, Western Region, Handrail (10BA6PC).

Scurfield, R.M. Wong, L. and Zeerocah, E. (1992). "An Evaluation of the Impact of Helicopter Ride Therapy for Inpatient Vietnam Veterans with PTSD." Military Medicine 157, 67-73,

Scurfield, R.M. (1993). "Treatment of Post-traumatic Stress Disorder in Vietnam Veterans." In J.P. Wilson and B. Raphael (eds.). The International Handbook of Traumatic Stress Syndromes (285-295). New York: Plenum Press. 
Frontiers: The Interdisciplinary Journal of Study Abroad

Scurfield, R.M. ((1994). "Treatment of War-Related Trauma: An Integrative Experiential, Cognitive and Spiritual Approach." In M.B. Williams and J.F. Somer (eds.). The Handbook of Post-Traumatic Therapy (181-203). Westport, CT: Greenwood Publishing.

Scurfield, R.M. and Burke, J. (1989). American Lake VA Program Evaluation Questionnaire: Return Trip to Vietnam. Tacoma, WA: Department of Veterans Affairs. (Unpublished instrument.)

Scurfield, R.M. (in press). "War-related Trauma: Psychosocial Interventions and Healing." In J. Conte (ed.), Handbook on Trauma and Abuse. Los Angeles: Sage Publications.

Snyder, R.J. (2000). "The Relationship between Learning Styles/Multiple Intelligences and Academic Achievement of High School Students." High School Journal 83(2), 11.

Terry, W. (1984). Bloods: An Oral History of the Vietnam War by Black Veterans. New York: Ballantine.

Tye, K.A. (1990). "Conclusion: A Look into the Future." In Global Education: From Thought to Action. Alexandria, VA: Association for Supervision and Curriculum Development.

Van DeVanter, L. (1983). Home before Morning: The Story of an Army Nurse in Vietnam. New York: Beaufort.

Walker, K. (1985). A Piece of My Heart. The Stories of Twenty-six American Women who Served in Vietnam. New York: Ballantine Books.

Wiest, A., Root, L. and Scurfield, R.M. (2001). "Post-traumatic Stress Disorder: The Legacy of War." In J. Jensen and A. Wiest (eds.). War in the Age of Technology (295-332). New York: New York University Press. 


\author{
A P PENDIX 1 \\ VIETNAM STUDY ABROAD COURSE SYLLABUS AND SCHEDULE \\ HISTORY $497 / 597$ or INTERNATIONAL STUDIES 498 and INTERNA- \\ TIONAL STUDIES 492 \\ [Each student will receive one unit of credit in International Studies 492 for \\ completing the course research paper]
}

\title{
READING S.
}

All program participants MUST read the following books BEFORE our trip to Vietnam.

Bao Ninh (1993), The Sorrow of War. A Novel of North Vietnam. New York: Pantheon Books.G. Moss (1990), Vietnam, An American Ordeal. Upper Saddle River, NJ: Prentice Hall.

T. Mangold and J. Penycate (1986), The Tunnels of Cu Chi. New York: Berkley Books.

H. Moore and J. Galloway (1993), We Were Soldiers Once . . and Young. New York: Harper Perrenial.

J. Shay (1994). Achilles in Vietnam.. New York: Simon and Shuster.

A. Wiest, L. Root and R. Scurfield (2001): Post-Traumatic Stress Disorder: The Legacy of War, in G. Jensen and A. Wiest, War in the Age of Technology, Myriad Faces of Modern Armed Conflict (295-332). New York: New York University Press.

Also, excerpts will be assigned from:

Confucius, the Analects

Nguen Du, The Tale of Kieu

The rationale behind reading these books is simple. While in country we will be studying Vietnam in a very detailed way. You are sacrificing to be there-and reading these books beforehand will better enable you to understand and appreciate your study-abroad experience. In reading these works, pay close attention to the following subjects, which will be emphasized during our trip:

Vietnamese culture and religion 
Frontiers: The Interdisciplinary Journal of Study Abroad

The war in the Mekong Delta

The Tet Offensive (especially in Hue and at Khe Sanh)

Post-traumatic stress disorder

Prisoners-of-war

Hamburger Hill

If you do your readings, the results will be worth the effort. You will stand alone atop the hill that was Khe Sanh and have an appreciation for what happened there. Please be ready to turn in a one-page summary of each book before we depart the United States.

\section{WRITTEN WORK.}

While in Vietnam, we require that you keep a daily journal of your experiences and thoughts. We learn several things from the journal and are working on an academic project taken from them. In addition, the journals will provide you with a wonderful way to remember your trip in future years.

\section{RE SEARCH.}

Each student will produce a research paper (undergraduates 8-10 pages; graduate students 15-20 pages) after their return to the United States. The papers will be on a topic of the student's choice (with the agreement of the instructor) and will be based on a topic chosen due to your experience in Vietnam.

\section{TESTING.}

Each student will complete an all essay take home exam after their return to the United States. The exam will consist of questions taken from academic lectures, battlefield experiences, readings and cultural experiences during the Vietnam trip.

\section{COURSE SCHEDULE:}

4.12.00, 5.9.00—Pre-course orientation meetings

5.13-Depart New Orleans, fly to Ho Chi Minh City via Los Angeles 
Raymond M. Scurfield, Leslie P. Root and Andrew Wiest

and Seoul, Korea

5.14-Arrive Vietnam (midnight)

5.15-Morning: Vietnam orientation lecture.

Afternoon: tour of Saigon, including the Presidential Palace, Dragon

House, Notre Dame Cathedral, Vinh Nguyen Pagoda, and site of

American embassy.

Evening: banquet and meeting with Vietnamese students.

5.16-Morning: Visit to North Vietnamese/Viet Cong cemetery. Visit to Army of the Republic of Vietnam cemetery (destroyed).

Afternoon: Lecture on psychology and war by Leslie Root and Ray Scurfield, viewing of a video, (Two Decades and A Wake-Up, Public Broadcasting System, 1990), and debriefing.

5.17-All-day journey to Long An Province and the Can Giouc battlefield of U.S. veteran John Young. Guided tour of the battlefield by Young and three Viet Cong veterans of the battle.

Travel to the battle site by van, boat, motorcycle and boat again. Evening-lecture by John Young on the meaning of returning to the site of his traumatic experience and debriefing.

5.18-Lecture by Andrew Wiest on the Vietnam War in the Mekong Delta. Lecure by John Van Sant on Vietnamese cultural history. Lecture by Leslie Root on Post-traumatic stress disorder.

5.19-Visit to the chief Cao Dai temple in Tay Ninh Province, near the border with Cambodia.

Visit to the Viet Cong tunnel complex at $\mathrm{Cu}$ Chi and lectures by local guides.

5.20-Morning lecture by U.S. veteran Charles Brown on his war experiences.

Lecture by Ray Scurfield on modes of coping with PTSD

Afternoon visit to Charles Brown's battle sites in the Bien Hoa area north of Saigon. Brown will lecture on search and destroy tactics. 
Frontiers: The Interdisciplinary Journal of Study Abroad

Evening—debriefing

5.21-Morning free

Afternoon-lecture by Andrew Wiest and Charles Brown on the

Vietnam War in the Central Highlands. Lecture by John Van Sant on

Vietnamese religions.

5.22-Morning departure via hydrofoil for Can Tho-the unofficial capitol of the Mekong Delta.

Afternoon-tour of Can Tho by cycylo.

5.23-Boat trip to the floating markets of Cai Rang and Phung Hiep. Evening-return to Saigon.

5.24-Morning departure for Hue via Vietnam Airlines. Tour of the Citadel, Thao Hoa Palace and the Lam Hien Pavilion. Local guides and faculty will lecture.

Evening-lecture by U.S. veteran Roy Ainsworth and Andrew Wiest on the Marine experience in Vietnam.

5.25-Morning departure for the Demilitarized Zone. The class will visit the Marine base at Con Thien and Roy Ainsworth's battle site at Phu An. Ainsworth will lecture on his experiences at these sites.

Evening debriefing and lecture on PTSD.

5.26-Morning debriefing concerning Ainsworth's battlefield.

Afternoon visit to the tomb of Ming Mang and te Thien Mu Pagoda. Local guides and faculty will lecture.

5.27-Morning departure. Drive through the Hai Van Pass (with a stop there), to Danang for a visit to the Cham Museum. Continue one to the town of Hoi An. Tour the ancient city.

5.28-Free day in Hoi An.

5.29-Lecture on Vietnam at war by Paul Harris of the Royal Academy Sandhurst. 
Raymond M. Scurfield, Leslie P. Root and Andrew Wiest

Lecture on the legacy of the Vietnam War by Andrew Wiest.

Lecture on military psychiatry during the Vietnam War and Vietnam 2000 by Ray Scurfield

Closing remarks by the U.S. veterans: Charles Brown, Roy Ainsworth and John Young.

Afternoon free.

5.30—-Departure for the United States. 